\title{
Kajian Kalimat Efektif pada Laporan Berita Reporter Metro TV
}

\author{
Marieta Bona Devita*, I G.N.K. Putrayasa, I Made Madia \\ Program Studi Sastra Indonesia, Fakultas Ilmu Budaya, Universitas Udayana \\ [marietadev@yahoo.co.id] \\ Denpasar, Bali, Indonesia \\ *Corresponding Author
}

\begin{abstract}
This research entitled "The News Report of Metro TV Reporter: The research of effective sentence". The aim of this research was to find out the description, error, and percentage of effective and ineffective sentence in the news report of Metro TV reporter. The used theory refer to some ideas from the experts, those are Keraf (1980), Razak (1986), Sugono (2001), Putrayasa (2014), and Agency of Language Development and Coaching (2014). The used method to collect the data in this research was observation method, then the data was analyzed with qualitative descriptive method, quantitative method, and agih method. Method of presenting analyzed data that used in this research were formal and informal method. Data source in this research was from twelve videos of news report of Metro TV reporter in 2018. The result of this research showed that Metro TV reporter's understanding of the use of effective sentences reach $30,22 \%$ from 12 news reports. This is proven by the discovery of 97 ineffective sentences out of 139 sentences. The error of ineffective sentence in news report of Metro TV reporter was divided into four kinds, those were the accuracy of information 7 sentences $(5.03 \%)$, stiffness 6 sentences $(4,32 \%)$, efficiency 48 sentences (34.53\%), multiple errors and plural 36 sentences $(25.90 \%)$. The total percentage of the error ineffective sentence as a whole was $69.78 \%$. Based on this percentage, the highest frequency of errors was in the aspect of efficiency.
\end{abstract}

Keywords: news report, reporter, effective sentence

\begin{abstract}
Abstrak
Penelitian ini berjudul "Laporan Berita Reporter Metro TV: Kajian Kalimat Efektif". Tujuan penelitian ini adalah untuk mengetahui deskripsi, kesalahan, dan persentase kalimat efektif dan tidak efektif pada laporan berita reporter Metro TV. Teori yang digunakan merujuk pada beberapa gagasan ahli, yaitu Keraf (1980), Razak (1986), Sugono (2001), Putrayasa (2014), dan Badan Pengembangan dan Pembinaan Bahasa (2014). Metode yang digunakan untuk mengumpulkan data pada penelitian ini adalah metode simak, kemudian data dianalisis dengan metode deskriptif kualitatif, metode kuantitatif, dan metode agih. Metode penyajian hasil analisis data yang digunakan adalah metode formal dan metode informal. Sumber data dalam penelitian ini adalah dua belas video laporan berita reporter Metro TV pada 2018. Hasil penelitian ini menunjukkan bahwa pemahaman reporter Metro TV terhadap penggunaan kalimat efektif mencapai 30,22\% dari 12 laporan berita. Hal tersebut dibuktikkan dengan ditemukannya 97 kalimat tidak efektif dari 139 kalimat. Kesalahan kalimat tidak efektif dalam laporan berita reporter Metro TV
\end{abstract}


dibagi menjadi empat jenis, yaitu ketepatan informasi sebanyak 7 kalimat $(5,03 \%)$, kebakuan sebanyak 6 kalimat (4,32\%), efisiensi sebanyak 48 kalimat (34,53\%), kesalahan ganda dan jamak sebanyak 36 kalimat (25,90\%). Jumlah persentase kesalahan kalimat tidak efektif secara keseluruhan adalah 69,78\%. Berdasarkan persentase tersebut, frekuensi kesalahan terbanyak ada pada aspek efisiensi.

Kata kunci: laporan berita, reporter, kalimat efektif

\section{PENDAHULUAN}

Bahasa adalah sebuah sistem lambang berupa bunyi yang bersifat arbitrer, digunakan oleh kelompok sosial untuk bekerja sama, berkomunikasi, dan mengidentifikasikan diri (Sugono, 2001:1). Di Indonesia, bahasa yang digunakan untuk berkomunikasi adalah bahasa Indonesia. Bahasa Indonesia adalah alat komunikasi yang paling penting untuk mempersatukan seluruh masyarakat Indonesia (Kasanova, 2016:233). Oleh karena itu, penggunaan bahasa Indonesia yang tidak baik dan benar dapat mengaburkan keaslian atau kemurnian bahasa Indonesia, serta dapat mengganggu komunikasi atau penyampaian informasi kepada penerima (Maruka, 2018:1). Bahasa Indonesia memiliki banyak ragam, salah satu di antaranya ragam bahasa jurnalistik.

Bahasa jurnalistik atau bahasa pers adalah bahasa yang digunakan oleh wartawan (Anwar, 1980:1). Menurut (Aryusmar, 2011:1210), bahasa jurnalistik adalah bahasa Indonesia yang baku, yang harus memperhatikan kaidahkaidah yang berlaku. Bahasa tentunya memiliki kaidah yang harus ditaati pemakaiannya agar tidak terjadi kealahan dalam penafsirannya (Azizah, 2015:73). Bahasa jurnalistik, khususnya ragam tulis harus memperhatikan ejaan bahasa Indonesia, menggunakan bahasa baku, dan menerapkan kaidah-kaidah tata bahasa. Bahasa jurnalistik berfungsi sebagai bahasa komunikasi pengantar pemberitaan yang digunakan media cetak dan media elektronik. Pada dasarnya penyampaian informasi melalui media elektronik atau media cetak bukan merupakan hal yang terpenting melainkan yang terpenting adalah bahasa yang digunakan dalam media massa yang terdapat dalam sebuah wacana berita (Puspitasari, 2017:2). Kemudahan yang dialami masyarakat sekarang dalam mengakses informasi dari sumber manapun menjadi daya tarik suatu berita akan sampai kepada pembacanya (Khotimah, 2017:1).

Berita diperoleh secara langsung dari beberapa wartawan. Wartawan merupakan komponen terpenting dalam media massa. Wartawan yang melakoni kegiatan jurnalistik di lapangan untuk menggali, mengolah, dan menyajikan informasi menjadi sebuah berita biasanya dinamakan reporter (Sujaya dalam Mbete, 2013:38--39). Berita disebar di berbagai surat kabar dan disiarkan di berbagai stasiun televisi. Salah satu stasiun televisi swasta yang menyiarkan berita adalah Metro TV. Metro TV didirikan oleh PT Media Televisi Indonesia dan resmi mengudara sejak 25 November 2000 (https://en.wikipedia.org/wiki/MetroTV, diakses 18 September 2018). Dulu, Metro TV khusus menyiarkan program-program berita, tetapi seiring dengan perkembangan zaman diselingi program lain yang tetap berisi informasi. Salah satu program berita yang disiarkan Metro TV adalah Metro News. Program tersebut menayangkan berita yang disampaikan oleh reporter. Sebagian berita disampaikan secara langsung di lokasi kejadian dan sebagian disampaikan di dalam studio. Reporter dituntut untuk menyampaikan berita sesuai dengan ragam bahasa jurnalistik dan kaidah tata 
bahasa baku, khususnya kalimat efektif. Pemahaman terhadap kalimat efektif diperlukan agar tidak terjadi kesalahpahaman dalam menafsirkan berita. Penelitian ini dilakukan untuk memahami efektivitas kalimat, jenis kesalahan kalimat tidak efektif, dan persentase peggunaan kalimat efektif dan tidak efektif dalam laporan berita reporter Metro TV.

Berdasarkan latarbelakang yang uraian di atas, rumusan masalah yang diteliti adalah sebagai berikut: Bagaimanakah efektivitas kalimat pada laporan berita reporter Metro TV?, Apa sajakah jenis kesalahan yang terdapat dalam kalimat tidak efektif pada laporan berita reporter Metro TV?, Berapakah persentase penggunaan kalimat efektif dan tidak efektif pada laporan reporter Metro TV?

Adapun tujuan dari penelitian ini adalah sebagai berikut. Pertama, untuk mengetahui deskripsi efektivitas kalimat pada laporan berita reporter Metro TV. Kedua, untuk mengetahui jenis kesalahan yang terdapat dalam kalimat tidak efektif pada laporan berita reporter Metro TV. Ketiga, untuk mengetahui persentase kalimat efektif dan tidak efektif pada laporan berita reporter Metro TV.

\section{METODE}

Metode dan teknik pengumpulan data yang digunakan dalam penelitian ini adalah metode simak dilanjutkan dengan transkripsi data dan teknik catat. Selanjutnya dipilih dengan teknik random sampling. Dalam proses penganalisisan data penelitian ini digunakan metode deskriptif kualitatif, metode agih, dan metode deskriptif kuantitatif. Selanjutnya, dalam proses penyajian hasil analisis data digunakan metode informal dan formal.

\section{HASIL DAN PEMBAHASAN}

\section{Deskripsi Penggunaan Kalimat Tidak Efektif pada Laporan Berita Reporter Metro TV}

Menurut Rahmawati (dalam Nurhayatin, 2018:104), kalimat efektif adalah kalimat yang dapat mengungkapkan gagasan secara tepat dan dapat dipahami oleh orang yang membacanya. Hal ini sesuai dengan pendapat Sugono (2001:39) yang menjelaskan bahwa kalimat efektif adalah kalimat yang memperlihatkan bahwa proses penyampaian oleh pembicara/penulis dan proses penerimaan oleh pendengar/pembaca berlangsung dengan sempurna sehingga isi atau maksud yang disampaikan oleh pembicara/penulis tergambar lengkap dalam pikiran pendengar/pembaca (Sugono, 2001:39). Agar proses penyampaian dan penerimaan tersebut berlangsung sempurna, kalimat yang diucapkan atau dituangkan dalam tulisan hendaknya kalimat efektif (Riswati, 2015:222). Sebaliknya, proses penyampaian dan penerimaan yang tidak sempurna dapat disebabkan oleh ketidakefektifan kalimat. Kalimat tidak efektif merupakan kalimat yang melanggar kaidah tata bahasa baku bahasa Indonesia. Ketidakefektifan kalimat juga dapat menyebabkan ketidakjelasan informasi yang ingin disampaikan. Dalam bahasa jurnalistik, informasi dapat disampaikan melalui berita. Berita yang disampaikan oleh reporter haruslah informatif dan komunikatif. Informatif berarti informasi yang ingin disampaikan dapat diterima dengan baik, sedangkan komunikatif berarti bahasa yang digunakan dapat dimengerti oleh pendengar/pembaca. Menurut (Usman, 2012:118) pengembangan kalimat efektif dapat dilakukan sebagai sarana unruk mengungkapkan dan penangkapan pesan 
agar komunikasi menjadi berterima atau komunikatif. Pemahaman reporter terhadap penggunaan kalimat efektif mampu meningkatkan performanya saat menyampaikan sebuah berita. Dalam penelitian ini ditemukan sebanyak 97 kalimat efektif dari 139 kalimat. Hal tersebut membuktikan bahwa sebagian besar kalimat laporan berita reporter Metro TV pada 2018 tidak efektif.

Jenis Kesalahan yang terdapat dalam Kalimat Tidak Efektif pada Laporan Berita Reporter Metro TV

Penelitian ini menggunakan teori linguistik terapan yang berkaitan dengan kalimat efektif dalam bahasa Indonesia. Teori kalimat efektif yang digunakan dalam penelitian ini merujuk pada beberapa gagasan ahli, yaitu Keraf (1980), Razak (1986), Sugono (2001), Putrayasa (2014), serta Badan Pengembangan dan Pembinaan Bahasa (2014). Berdasarkan kelima gagasan tersebut syarat atau ciri kalimat efektif dapat dikelompokkan menjadi tiga aspek. Ketiga aspek tersebut, yaitu ketepatan informasi (tipe A), kebakuan (tipe B), dan efisiensi (tipe C). Ketiga aspek tersebut juga menghasilkan kesalahan ganda, seperti tipe D (ketepatan informasi dan efisiensi), tipe E (kebakuan dan efisiensi), serta tipe $\mathrm{F}$ atau kesalahan jamak (ketepatan informasi, kebakuan, dan efisiensi). Dengan demikian, total jenis kesalahan yang terdapat dalam laporan berita reporter Metro TV adalah empat jenis dengan enam tipe.

\section{Kalimat Tidak Efektif Berdasarkan Ketepatan Informasi}

Dalam berkomunikasi selalu menggunakan kalimat. Kalimat adalah salah satu unsur utama tata bahasa yang dapat berdiri sendiri sebagai satu kesatuan (Pericha, 2017:1). Kalimat efektif lebih menekankan efek informasi yang bisa sampai kepada pembaca/lawan bicara (Madia, 2017:2). Informasi yang disampaikan harus padat karena padat dalam bahasa jurnalistik berarti sarat informasi. Informasi yang kurang jelas dapat disebabkan oleh kalimat yang terlalu panjang, terlalu bertele-tele atau bisa disebut dengan kalimat tidak efektif. Kalimat dikatakan tidak efektif berdasarkan ketepatan informasi karena tidak memenuhi ciri kesatuan, penekanan, kevariasian, nalar, dan kesejajaran. Berikut adalah contoh kalimat tidak efektif pada laporan berita reporter Metro TV berdasarkan ketepatan informasi.

(1.a)*Di Sumatera Selatan sendiri akan ada sembilan kabupaten kota yang melaksanakan pilkada dengan jumlah TPS sebanyak 16.899. (Klm 6/LB 6)

Kalimat (1.a) tidak efektif karena kesatuan gagasannya kabur atau tidak jelas. Kesatuan gagasan menjadi kabur dapat disebabkan oleh kedudukan subjeknya tidak jelas atau penggunaan kata hubung yang tidak tepat. Penempatan preposisi $d i$ di depan frasa nominal Sumatera Selatan sendiri dapat menghilangkan fungsi subjek. Dengan demikian, kalimat (1a) diubah susunannya menjadi sebagai berikut.

\section{(1.b) Sembilan kabupaten-kota di Sumatera Selatan akan melaksanakan pilkada dengan jumlah TPS sebanyak 16.899.}

\section{Kalimat Tidak Efektif Berdasarkan Kebakuan}

Bahasa jurnalistik berpijak pada prinsip menarik, benar, dan baku (Sumadiria dalam Widarmanto, 2015:59). Dengan demikian, bahasa jurnalistik harus mengikuti kaidah tata bahasa baku. 
Menurut Sumadiria (dalam Widarmanto, 2015:63), bahasa baku berarti bahasa resmi sesuai dengan ketentuan tata bahasa serta pedoman ejaan yang disempurnakan berikut pedoman pembentukan istilah yang menyertainya. Bahasa baku menjadi salah satu faktor pendukung kalimat efektif. Pembicara/penulis yang ingin menyampaikan gagasannya, haruslah menguasai bahasa baku agar tidak terjadi kesalahpahaman. Kalimat dikatakan tidak efektif berdasarkan kebakuan karena tidak memenuhi ciri keutuhan. Di bawah ini contoh kalimat tidak efektif pada laporan berita reporter Metro TV berdasarkan kebakuan.

(2.a)*Kemudian, tadi selesai sekitar pukul 16.00 WIB menghadirkan saksi dari pemerintah dan juga dari pihak swasta. (Klm 2/LB 10)

Kalimat (2.a) tidak efektif karena tidak memiliki subjek. Untuk membuat suatu kalimat yang baik dan kalimat yang efektif hendaknya memahami unsurunsur yang membentuk sebuah kalimat (Indrayani, 2015:8). Unsur tersebut ditandai dengan minimal adanya subjek dan predikat. Apabila sebuah kalimat tidak memiliki kedua unsur atau hanya salah satu unsur, kalimat tersebut termasuk kalimat tidak efektif. Perbaikan kalimat tersebut menjadi sebagai berikut.

(2.b) Kemudian, sidang yang berakhir sekitar pukul 16.00 WIB menghadirkan saksi dari pemerintah dan pihak swasta.

\section{Kalimat Tidak Efektif Berdasarkan Efisiensi}

Kalimat efisien adalah kalimat yang memperhatikan kehematan dalam penggunaan kata (Madia, 2017:2). Penggunaan kata yang hemat dapat memadatkan dan memperjelas informasi yang ingin disampaikan pembicara/penulis kepada pendengar/pembaca. Informasi yang singkat, padat, dan jelas tentu menjadi asas seorang reporter dalam menyampaikan berita. Kalimat efektif ditandai pula dengan penggunaan kata secara hemat (Sugono, 2001:43). Hemat tidak berarti jumlah katanya harus ditulis/diucapkan lebih sedikit, tetapi seberapa banyak kata penting yang dapat dimengerti pendengar/pembaca. Di bawah ini contoh kalimat tidak efektif berdasarkan efisiensi.

(3.a)*Kemudian usai dilakukan proses coklit sampai tanggal 18 Februari 2018, pihak KPU Provinsi Jawa Timur nantinya akan melakukan proses atau sidang pleno untuk mengkomparasikan atau membandingkan data yang diterima KPU dari Kemendagri dan juga data yang menjadi temuan di lapangan dari temanteman KPU. (Klm 10/LB 1)

Faktor penyebab kalimat (3.a) tidak efektif adalah pleonasme. Pleonasme berarti pemakaian kata-kata yang berlebihan (Putrayasa, 2014:106). Penggunaan frasa nominal proses dan sidang pleno memiliki arti yang sama. Namun, frasa nominal sidang pleno lebih jelas maksudnya dibandingkan dengan frasa nominal proses. Dengan demikian, frasa nominal proses dapat dihilangkan. Sama halnya dengan frasa verbal mengkomparasikan dan membandingkan juga memiliki arti yang sama sehingga harus dihilangkan salah satu.

(3.b) Kemudian, usai dilakukan proses coklit sampai 18 Februari 2018, pihak KPU Provinsi Jawa Timur akan melakukan sidang pleno untuk membandingkan data yang diterima KPU dari Kemendagri 


\section{dengan data temuan di lapangan dari teman-teman.}

\section{Kalimat Tidak Efektif Berdasarkan Kesalahan Ganda dan Jamak}

Katidakefektifan kalimat pada laporan berita reporter Metro TV juga ada yang disebabkan oleh dua aspek dan tiga aspek. Kesalahan yang melibatkan dua aspek disebut kesalahan ganda, sedangkan kesalahan yang melibatkan tiga aspek disebut kesalahan jamak. Tipe kesalahan ganda dapat dikelompokkan menjadi dua tipe, yaitu tipe D (ketepatan informasi dan efisiensi) dan E (kebakuan dan efisiensi). Di sisi lain, tipe kesalahan jamak hanya meliputi satu tipe yaitu tipe F (ketepatan informasi, kebakuan, dan efisiensi). Berikut ini contoh kalimat tidak efektif berdasarkan tipe kesalahan ganda dan jamak pada laporan berita reporter Metro TV.

Tabel 1

Analisis Kalimat Tidak Efektif Berdasarkan Kesalahan Ganda dan Jamak

\begin{tabular}{cc}
\hline No. & \multicolumn{1}{c}{ Kalimat Tidak Efektif } \\
\hline & \\
& \\
& *Dan dalam kunjungannya tersebut, Gus \\
& Ipul menyempatkan diri untuk bertemu \\
1 & dengan para buruh dan sengaja untuk \\
& datang langsung melihat kondisi \\
& pembuatan produksi pabrik rambut \\
& palsu. (Klm 7/LB 4)
\end{tabular}

*Untuk bisa melakukan proses coklit terhadap 30 juta calon pemilih ini, maka pihak KPU setempat ini menyiapkan total 68.048 petugas. (Klm 4/LB 1)

Penggunaan kata hubung dan termasuk mubazir karena harusnya digunakan untuk menghubungkan dua klausa dalam satu kalimat. Selanjutnya frasa preposisional dalam kunjungannya tersebut dapat menghilangkan fungsi subjek sehingga harus dihilangkan.

Perbaikan: Gus Ipul menyempatkan diri untuk bertemu dengan para buruh dan melihat langsung kondisi pembuatan produksi pabrik rambut palsu.

Kalimat ini tidak memiliki subjek. Selain itu, penggunaan kata hubung untuk di awal kalimat termasuk mubazir.

Perbaikan: KPU setempat menyiapkan 20.048 petugas agar bisa melakukan proses coklit terhadap 30 juta calon pemilih.

Kalimat ini tidak memiliki subjek sehingga tidak memenuhi syarat sebuah kalimat. Di sisi lain, Penggunaan kata hubung dan dan sejalan dengan itu termasuk mubazir, sedangkan kata juga termasuk pleonasme. Selain itu, terdapat frasa verbal akan dilakukan yang berarti belum dilakukan, tetapi terdapat juga frasa verbal sudah berlangsung sehingga menyebabkan keambiguan.

Perbaikan: Selain itu, BNPB sudah melakukan proses rekonstruksi dan rehabilitasi pemukiman warga di beberapa desa yang berada di Lombok.

Tipe
desa yang berada di Lombok. (Klm 4/ LB 8)

*Dan selain itu, sejalan dengan itu juga akan dilakukan proses rekonstruksi dan juga rehabilitasi pemukiman warga, $\mathrm{di}$ 


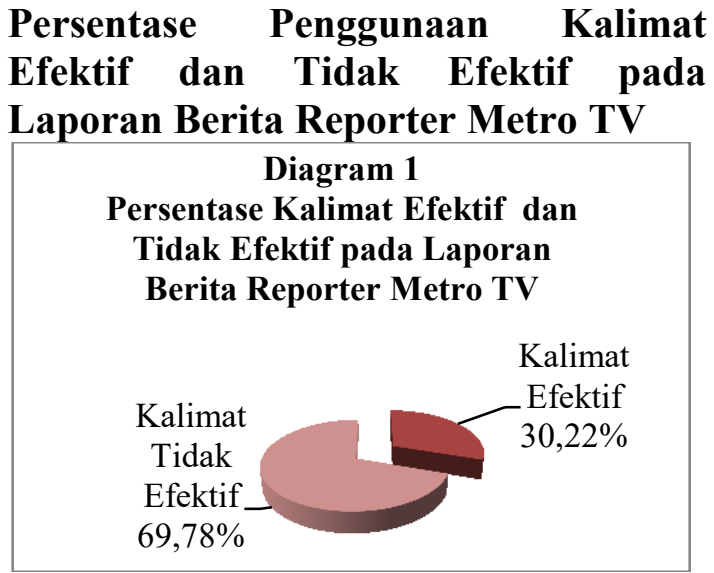

Sumber data penelitian ini sebanyak dua belas video laporan berita reporter Metro TV. Kedua belas video tersebut ditranskripkan ke dalam bentuk teks ortografis. Kemudian, pada laporan berita reporter tersebut ditemukan sebanyak 139 kalimat. Jenis kalimat dalam laporan reporter Metro TV dibagi menjadi dua, yaitu kalimat efektif dan tidak efektif. Diagram (1) di atas menunjukkan sebanyak 42 kalimat efektif $(30,22 \%)$ dan 97 kalimat tidak efektif $(69,78 \%)$.

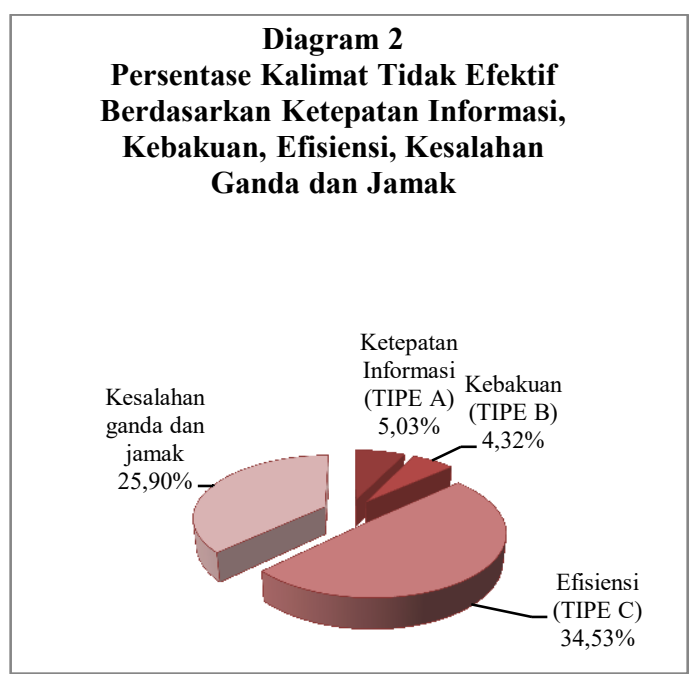

Diagram (2) menunjukkan sebanyak tujuh kalimat tidak efektif berdasarkan ketepatan informasi $(5,03 \%)$, enam kalimat tidak efektif berdasarkan kebakuan (4,32\%), 48 kalimat tidak efektif berdasarkan efisiensi (34,53\%), dan 36 kalimat tidak efektif berdasarkan kesalahan ganda dan jamak $(25,90 \%)$.

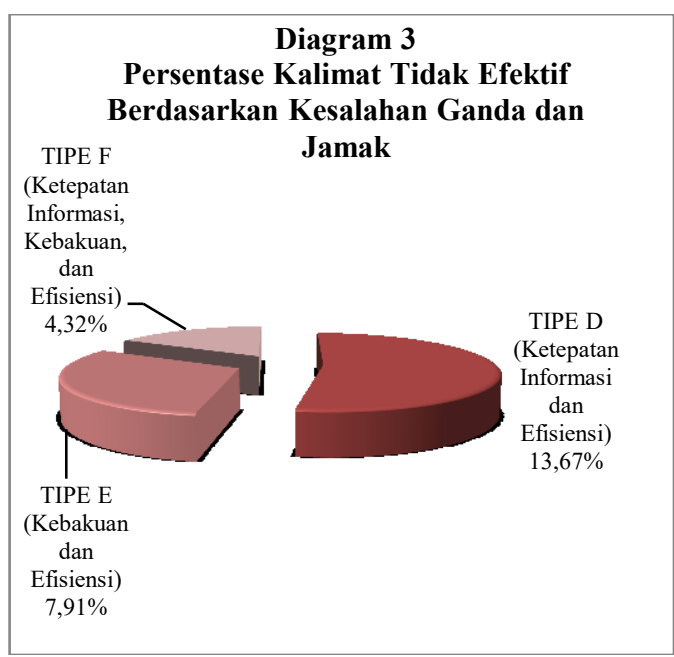

Diagram (3) menunjukkan sebanyak sembilan belas kalimat tidak efektif berdasarkan tipe D $(13,67 \%)$, dan sebelas kalimat tidak efektif berdasarkan tipe E (7,91\%). Dalam kesalahan jamak atau tipe $\mathrm{F}$ ditemukan sebanyak enam kalimat tidak efektif $(4,32 \%)$.

\section{SIMPULAN}

Berdasarkan analisis data, ditemukan sebanyak 139 kalimat pada laporan berita reporter Metro TV. Dalam 139 kalimat tersebut ditemukan sebanyak 97 kalimat tidak efektif $(69,78 \%)$ dan 42 kalimat efektif (30,22\%). Dengan demikian, dapat dikatakan bahwa sebagian besar kalimat dalam laporan berita reporter Metro TV tidak efektif. Dalam 97 kalimat tidak efektif ditemukan empat jenis kesalahan, yaitu berdasarkan ketepatan informasi, kebakuan, efisiensi, dan kesalahan ganda dan jamak. Jenis kesalahan yang paling banyak ditemukan adalah kesalahan berdasarkan efisiensi, yaitu 48 kalimat $(34,53 \%)$. Jenis kesalahan itu disusul oleh kesalahan ganda dan jamak, yaitu 36 kalimat $(25,90 \%)$, sedangkan yang paling sedikit adalah jenis kesalahan berdasarkan aspek kebakuan, yaitu enam kalimat $(4,32 \%)$ dan disusul oleh kesalahan berdasarkan aspek ketepatan informasi, yaitu tujuh 
kalimat (5,03\%). Dengan demikian, dapat dikatakan bahwa sebagian besar kalimat tidak efektif disebabkan oleh aspek efisiensi.

\section{SARAN}

Reporter diharapkan agar lebih mempelajari kalimat efektif, menggunakan bahasa baku, dan menerapkannya ketika menyampaikan berita. Hal tersebut diharapkan dapat mengantisipasi kesalahpahaman serta melancarkan proses penyampaian dan penerimaan informasi.

\section{REFERENSI}

Anwar, Rosihan. 1980. Bahasa Jurnalistik Indonesia dan Komposisi. Cetakan Kedua. Jakarta: Departemen Penerangan RI.

Aryusmar. (2011). Karakteristik Bahasa Jurnalistik dan Penerapannya pada Media Cetak. Vol 2, No. 2, pp 12091218.

Azizah, Nurul. (2015). Keefektifan Kalimat pada Skripsi Mahasiswa Fakultas Ilmu Pendidikan Universitas Negeri Jakarta. Vol. 06, No. 2, pp. 73-80.

Fitriyani, Dwi. (2015). Penguasaan Kalimat Efektif dan Penguasaan Diksi dengan Kemampuan Menulis Eksposisi pada Siswa SMP. Vol. 1, pp 129-139.

https://en.wikipedia.org/wiki/MetroTV, diakses 18 September 2018.

Indrayani, Sang A.P.S. dkk. (2015). Analisis Kalimat Efektif Cerpen Siswa Kelas IX SMA Negeri 1 Tampaksiring. Vol. 3, No. 1.
Kasanova, Ria. (2016). Penggunaan Efektif pada Skripsi Mahasiswa Fakultas Ekonomi Jurusan Manajemen Universitas Madura. Vol. 1, pp. 231-253.

Keraf, Gorys. 1980. Komposisi: Sebuah Pengantar Kemahiran Bahasa. Cetakan Keenam. Flores: Nusa Indah.

Khotimah, Khusnul. (2017). Ciri Kalimat pada Berita Utama Surat Kabar: Analisis Kritis terhadap Harian Terbitan Daerah. Vol. 2, pp. 1-7.

Madia, I Made. 2017. "Penataan Kalimat dan Paragraf di dalam Bahasa Jurnalistik". Makalah Fakultas Ilmu Budaya. Universitas Udayana, Denpasar.

Mbete, Aron Meko dkk. 2013. Dinamika Bahasa Media Televisi, Internet, dan Surat Kabar. Denpasar: Udayana University Press.

Maruka, Sarima R. (2018). Penggunaan Kalimat Efektif dalam Poster pada Majalah Dinding di Fakultas Keguruan dan Ilmu Pendidikan Universitas Tadulako. Vol. 3, pp. 1-9.

Nurhayatin, Titin dkk. (2018). Analisis Keefektifan Penggunaan Kalimat dalam Karya Tulis Ilmiah Mahasiswa Pendidikan Guru Sekolah Dasar. Vol. 4, pp. 102-114.

Pericha, Alivia D.R. (2017). Kalimat Tidak Efektif dalam Rubrik Jati Diri Surat Kabar Jawa Pos Edisi 2016. Vol. 2(2), pp 510-518.

Puspitasari, Eka. (2017). Karakteristik Bahasa Jurnalistik dalam Artikel Surat Kabar Priangan. Vol. 1, pp. 111. 
Putrayasa, I.B. 2014. Kalimat Efektif (Diksi, Struktur, dan Logika). Cetakan Keempat. Bandung: PT Refika Aditama.

Razak, Abdul. 1986. Kalimat Efektif: Struktur, Gaya, dan Variasi. Cetakan Kedua. Jakarta: PT Gramedia.

Riswati. (2015). Penggunaan Kalimat Efektif dalam Karya Tulis Ilmiah Mahasiswa. Vol. 1, No. 2, pp. 221227

Sugono, Dendy dkk. 2001. Kalimat. Jakarta: Pusat Bahasa.

Usman, Raja. (2012). Penggunaan Kalimat Efektif dalam Berkomunikasi Lisan dan Tulisan Siswa Kelas III SMP AL Ittihad Rumbai Pekanbaru. Vol 7, pp 118124.

Widarmanto, Tjahjono. 2015. Pengantar Jurnalistik: Panduan Awal Penulis dan Jurnalis. Yogyakarta: Araska. 